\title{
Endovascular Coiling of Wide-Neck and Wide-Neck Bifurcation Aneurysms: A Systematic Review and Meta-Analysis
}

\author{
(D) B. Zhao, DR. Yin, (D) G. Lanzino, DD.F. Kallmes, DH.J. Cloft, and (DW. Brinjikji
}

\begin{abstract}
BACKGROUND AND PURPOSE: We present the results of a systematic review and meta-analysis examining outcomes of endovascular coiling of wide-neck and wide-neck bifurcation aneurysms with and without stent assistance. The aim of our study was to assess angiographic and clinical outcomes.
\end{abstract}

MATERIALS AND METHODS: We performed a comprehensive literature search for all articles on the endovascular coiling of wide-neck and wide-neck bifurcation aneurysms. Studies meeting our inclusion criteria and abstracted data were selected by 2 independent reviewers. Primary outcomes were $>6$-month complete or near-complete angiographic occlusion, aneurysm recanalization, and aneurysm retreatment. Secondary outcomes included initial complete or near-complete occlusion, long-term good neurologic outcome, procedure-related morbidity, and procedure-related mortality. Data were analyzed by using random-effects meta-analysis.

RESULTS: In total, 38 studies including 2446 patients with 2556 aneurysms were included. For all wide-neck aneurysms, immediate complete or near-complete occlusion rate was $57.4 \%$ (95\% Cl, $48.1 \%-66.8 \%)$. Follow-up near-complete occlusion rate was $74.5 \%$ ( $95 \% \mathrm{Cl}$, $68.0 \%-81.0 \%)$. Recanalization and retreatment rates were $9.4 \%$ (95\% Cl, 7.1\%-11.7\%) and $5.8 \%(95 \% \mathrm{Cl}, 4.1 \%-7.5 \%)$, respectively. Long-term good neurologic outcome was $91.4 \%$ (95\% Cl, 88.5\%-94.2\%). For wide-neck bifurcation aneurysms, initial complete or near-complete occlusion rate was $60.0 \%$ (95\% Cl, 42.7\%-77.3\%), long-term complete or near-complete occlusion rate was $71.9 \%$ (95\% Cl, 52.6\%-91.1\%), and the recanalization and retreatment rates were $9.8 \%(95 \% \mathrm{Cl}, 7.1 \%-12.5 \%)$ and $5.2 \%(95 \% \mathrm{Cl}, 1.9 \%-8.4 \%)$, respectively.

CONCLUSIONS: Our study of angiographic and clinical outcomes for patients with wide-neck aneurysms demonstrates that endovascular coiling with or without stent-assisted coiling is safe, with low rates of perioperative morbidity and mortality. Initial and long-term angiographic outcomes were generally satisfactory, but not ideal. These data provide some baseline comparisons against which emergent technologies can be assessed.

W

ith the advent of stent-assisted and balloon-assisted coiling, wide-neck and wide-neck bifurcation intracranial aneurysms are increasingly treated with endovascular techniques to prevent hemorrhage or recurrent bleeding. Both stent-assisted and balloon-assisted coiling have been shown to be safe and effective in the treatment of these aneurysms by allowing for increased packing density and lower rates of parent artery occlusion compared with conventional coiling

Received October 22, 2015; accepted after revision March 1, 2016

From the Departments of Neurosurgery (B.Z., G.L.) and Radiology (D.F.K., H.J.C., W.B.), Mayo Clinic, Rochester, Minnesota; and Department of Neurology (R.Y.), The General Hospital of Lanzhou Military Command, Lanzhou, China.

Please address correspondence to Waleed Brinjikji, MD, Mayo Clinic, Department of Radiology, 200 First St SW, Rochester, MN 55905; e-mail:

brinjikji.waleed@mayo.edu; @wbrinjikji

三 Indicates article with supplemental on-line table

http://dx.doi.org/10.3174/ajnr.A4834 alone. ${ }^{1-5}$ Even in the era of endoluminal and intrasaccular flow diverters, many wide-neck and wide-neck bifurcation aneurysms will continue to be treated with conventional coiling, particularly with stent assistance. ${ }^{6-8}$

We present the results of a systematic review and metaanalysis examining outcomes of endovascular coiling of wideneck and wide-neck bifurcation aneurysms with and without stent-assisted coiling. The aim of our study was to assess both angiographic and clinical outcomes in order to provide overall data against which current and future emergent techniques can be compared.

\section{MATERIALS AND METHODS Literature Search}

A comprehensive literature search of the PubMed, Ovid MEDLINE, and Ovid EMBASE data bases was designed and conducted by an experienced librarian with input from the authors. The keywords 
intracranial aneurysm, cerebral aneurysm, aneurysm, wide-neck, bifurcation, complex, stent, balloon, endovascular, coiling, and coils were used in both "AND" and "OR" combinations. The search was limited to articles published from 1992 to week 18 of 2015 and is summarized in the On-line Table. All studies reporting patients with wide-neck or wide-neck bifurcation aneurysms treated with endovascular coiling with or without stent assistance were included. We used the following inclusion criteria: 1) English language, 2) study reporting a consecutive series of wide-neck and/or wide-neck bifurcation aneurysms treated with coiling, 3) series of at least 10 patients reporting angiographic and/or clinical outcomes, and 4) at least 6 months of angiographic follow-up. Review articles, comments, guidelines, technical notes, and editorials were excluded. The included studies were selected by 2 of the authors (B.Z., R.Y.), both with at least 1 year of experience in meta-analysis. Differences were resolved by a senior author (W.B.) with 5 years of experience in meta-analysis. Patients receiving endovascular treatment with flow diverters and intrasaccular flow diverters such as the Woven EndoBridge (WEB) aneurysm embolization system (Sequent Medical, Aliso Viejo, California) were excluded.

\section{Outcomes and Data Extraction}

For each study, we extracted the following baseline information: number of patients, aneurysm rupture status, sex, mean age, number of aneurysms treated, mean aneurysm size, mean aneurysm neck size, definition of wide neck, clinical outcome score used, length of clinical follow-up, and length of angiographic follow-up.

The primary outcomes of this study were $>6$-month followup, complete or near-complete angiographic occlusion, aneurysm recanalization, and aneurysm retreatment. Complete occlusion was defined as $100 \%$ occlusion or absence of angiographic filling in aneurysm neck or sac. Near-complete occlusion was defined as either $90 \%-99 \%$ occlusion or small residual neck filling without any filling of the sac.

Secondary outcomes included initial complete or near-complete occlusion, long-term good neurologic outcome, procedurerelated morbidity, and procedure-related mortality. Good neurologic outcome was defined as an mRS score of $0-2$ or Glasgow Outcome Score of 4-5 (good recovery, moderate disability). In cases where these scores were not available, good neurologic outcome was determined if the study used terms such as "no morbidity," "good recovery," or "moderate disability."

In addition to studying overall outcomes of patients with wide-neck aneurysms receiving endovascular coiling, we performed 3 subgroup analyses including patients treated with nonstent-assisted coiling (ie, with or without balloon remodeling), patients treated with stent-assisted coiling, and patients with wide-neck bifurcation aneurysms. Outcomes of ruptured and unruptured aneurysms could not be separated because most studies did not stratify outcomes by rupture status.

\section{Study Risk of Bias}

We modified the New Castle Ottawa Quality Assessment Scale for Case Control Studies to assess the risk of bias of the studies included in this meta-analysis. This tool is designed for use in com- parative studies; however, because none of the included studies were controlled, we assessed study risk of bias based on selected items from the tool focusing on the following questions: 1) Did the study include all patients or consecutive patients versus a selected sample?; 2) Was the study retrospective or prospective?; 3) Was angiographic and clinical follow-up satisfactory, thus allowing for ascertainment of all outcomes?; 4) Were outcomes clearly reported?; and 5) Were the interventionalists treating the patients the same as those who assessed angiographic and clinical outcomes?

\section{Statistical Analysis}

We estimated from each cohort the cumulative incidence (event rate) and 95\% CI for each outcome. Event rates for each intervention were pooled in a meta-analysis across studies by using the random-effects model. ${ }^{9}$ Anticipating heterogeneity between studies, we chose this model a priori because it incorporates within-study variance and between-study variance. Heterogeneity of treatment effect across studies was evaluated by using the $\mathrm{I}^{2}$ statistic, in which $\mathrm{I}^{2}>50 \%$ suggests substantial heterogeneity. ${ }^{10} \mathrm{~A} \chi^{2}$ analysis was used to compare outcomes between the stent-assisted and non-stent-assisted coiling groups. Statistical analysis was performed by using the software program OpenMeta[Analyst] (http://www.cebm.brown.edu/openmeta/).

\section{RESULTS}

\section{Study Selection and Characteristics}

The initial literature search yielded 900 articles. Upon review of the abstracts and titles, 649 articles were excluded. We selected 239 articles for full-text screening. After screening, we excluded 213 articles, most of which were excluded because they did not separate outcomes of wide-neck versus narrow-neck aneurysms or had insufficient data. In total, we included 38 articles including 2446 patients with 2556 aneurysms. Of these, 656 patients had ruptured aneurysms and 1793 patients had unruptured aneurysms; in 107 aneurysms, the rupture status was not known. Among all aneurysms in the study, 496 were wide-neck bifurcation aneurysms. Regarding interventions, 376 were treated with coiling alone and 2090 were treated with stent-assisted coiling.

Of the 38 studies, 4 had a low risk of bias, 11 had a high risk of bias, and 23 had a medium risk of bias. The most commonly used definition for wide-neck aneurysm was a neck size of $\geq 4 \mathrm{~mm}$ and/or a dome-to-neck ratio of $\leq 2$ (17 studies). In 5 studies, wide-neck aneurysms were defined as those with a neck size of $\geq 4$ $\mathrm{mm}$ and/or a dome-to-neck ratio of $\leq 1.5$. All included studies had at least 6 months of angiographic follow-up. The smallest study had 10 patients with 10 aneurysms, and the largest study had 468 patients with 500 aneurysms. A summary of included studies is provided in the On-line Table. The flow chart for study selection is provided in Fig 1.

\section{Angiographic Outcomes}

Overall, the rate of initial complete or near-complete occlusion was $57.4 \%$ (95\% CI, 48.1\%-66.8\%) (Fig 2). Follow-up complete occlusion rates were $74.5 \%$ (95\% CI, $68.0 \%-81.0 \%$ ) overall, $80.1 \%$ (95\% CI, 70.9\%-89.2\%) for coiling alone, and $73.0 \%$ (95\% CI, 65.1\%-81.0\%) for stent-assisted coiling $(P=.38)$ 
(Fig 3). Wide-neck bifurcation aneurysms had long-term complete occlusion rates of $71.9 \%$ (95\% CI, 52.6\%-91.1\%).

Aneurysm recanalization rates were 9.4\% (95\% CI, 7.1\%-

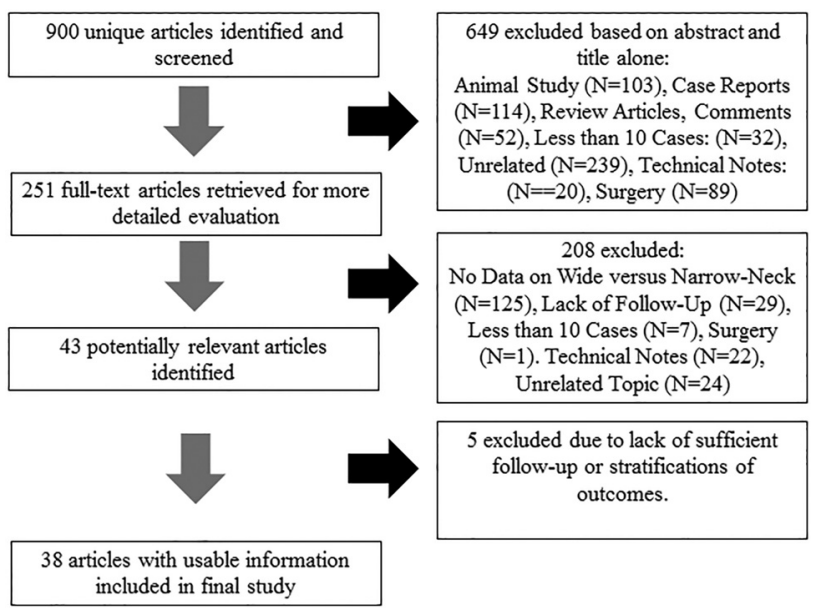

FIG 1. Flow chart of literature search.

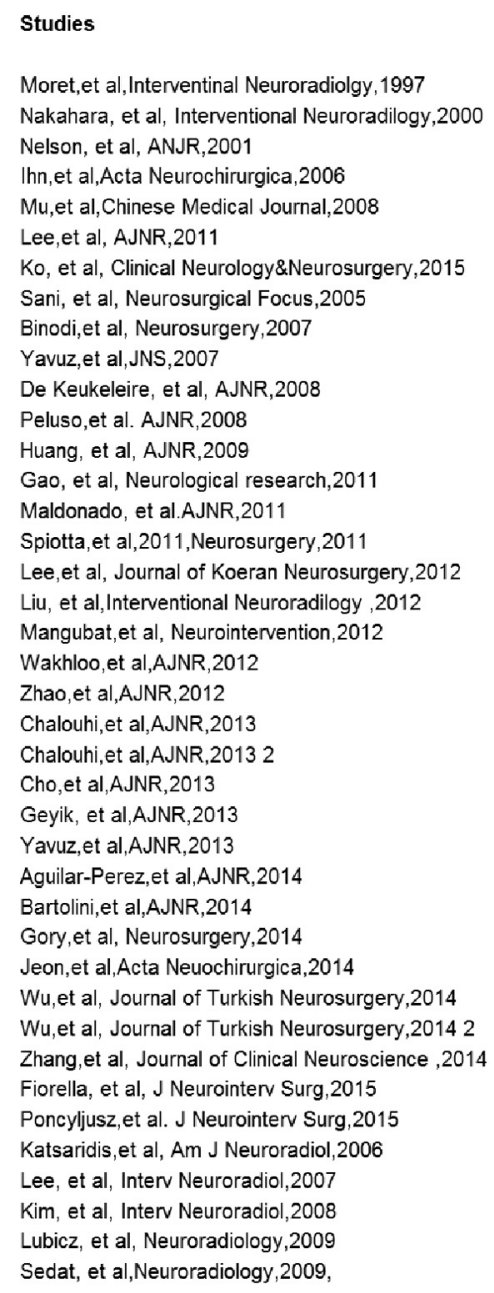

Overall $\left(I^{\wedge} 2=95.48 \%, P<0.001\right)$

Estimate (95\% C.I.) EV/Trt

$0.710(0.550,0.869) \quad 22 / 31$

$0.643(0.392,0.894) \quad 9 / 14$

$0.750(0.560,0.940) \quad 15 / 20$

$0.929(0.738,1.000) \quad 6 / 6$

$0.900(0.807,0.993) \quad 36 / 40$

$0.912(0.839,0.986) \quad 52 / 57$

$0.969(0.883,1.000) \quad 15 / 15$

$0.900(0.714,1.000) \quad 9 / 10$

$0.567(0.389,0.744) \quad 17 / 30$

$0.944(0.839,1.000) \quad 17 / 18$

$0.500(0.154,0.846) \quad 4 / 8$

$0.571(0.312,0.831) \quad 8 / 14$

$0.917(0.760,1.000) \quad 11 / 12$

$0.855(0.801,0.910) \quad 136 / 159$

$0.647(0.533,0.761) \quad 44 / 68$

$0.632(0.415,0.848) \quad 12 / 19$

$0.958(0.845,1.000) \quad 11 / 11$

$0.556(0.231,0.880) \quad 5 / 9$

$0.667(0.449,0.884) \quad 12 / 18$

$0.650(0.565,0.735) \quad 78 / 120$

$0.818(0.590,1.000) \quad 9 / 11$

$0.500(0.327,0.673) \quad 16 / 32$

$0.754(0.652,0.855) \quad 52 / 69$

$0.704(0.531,0.876) \quad 19 / 27$

$0.983(0.971,0.995) \quad 459 / 467$

$0.247(0.185,0.309) \quad 46 / 186$

$0.591(0.385,0.796) \quad 13 / 22$

$0.859(0.785,0.933) \quad 73 / 85$

$0.600(0.471,0.729) \quad 33 / 55$

$0.810(0.642,0.977) \quad 17 / 21$

$0.742(0.651,0.833) \quad 66 / 89$

$0.755(0.635,0.876) \quad 37 / 49$

$0.625(0.388,0.862) \quad 10 / 16$

$0.750(0.590,0.910) 21 / 28$

$0.821(0.735,0.906) \quad 64 / 78$

$0.985(0.943,1.000) 32 / 32$

$0.469(0.296,0.642) \quad 15 / 32$

$0.740(0.642,0.838) \quad 57 / 77$

$0.794(0.658,0.930) \quad 27 / 34$

$0.711(0.566,0.855) \quad 27 / 38$

$0.745(0.680,0.810) 1612 / 2127$
$11.7 \%$ ) overall, $10.3 \%$ (95\% CI, 4.3\%-16.4\%) for coiling alone, $9.2 \%$ (95\% CI, 6.7\%-11.7\%) for stent-assisted coiling, and $9.8 \%(95 \% \mathrm{CI}, 7.1 \%-12.5 \%)$ for wide-neck bifurcation aneurysms $(P=.17)$. Aneurysm retreatment rates were $5.8 \%$ (95\% CI, 4.1\%-7.5\%) overall, 5.5\% (95\% CI, 1.7\%-9.2\%) for coiling alone, $5.7 \%$ (95\% CI, 3.8\%-7.7\%) for stent-assisted coiling, and 5.2\% (95\% CI, 1.9\%-8.4\%) for wide-neck bifurcation aneurysms $(P=.47)$.

\section{Clinical Outcomes}

Overall procedure-related permanent morbidity rate for coiling with and without stent-assistance was $2.6 \%$ (95\% CI, $1.7 \%-$ $3.4 \%)$. Stent-coil procedure-related permanent morbidity rate was $1.9 \%$ (95\% CI, 0.0\%-3.7\%), and wide-neck bifurcation procedure-related permanent morbidity rate was $4.4 \%$ (95\% CI, $1.9 \%-7.0 \%)$. Procedure-related mortality rate was $1.0 \%$ (95\% CI, $0.6 \%-1.5 \%)$.

The overall rate of good neurologic outcome for coiling with and without stent assistance was 91.4\% (95\% CI, 88.5\%-94.2\%). Stent-coil long-term good neurologic outcome rate was $89.0 \%$

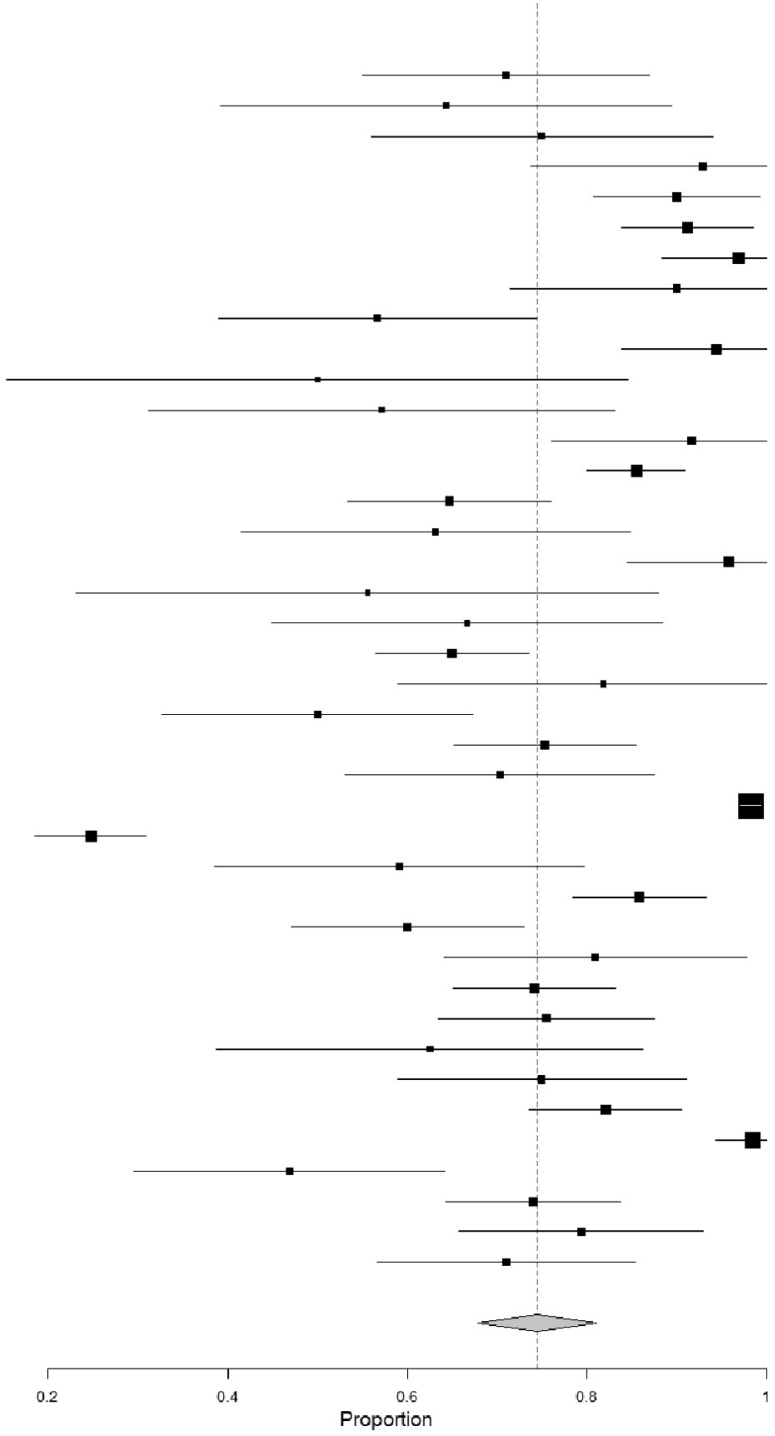

FIG 2. Forest plot for long-term complete or near-complete angiographic occlusion rates. 
Studies

Moret,et al, Interventinal Neuroradiolgy,1997

Nakahara, et al, Interventional Neuroradilogy,200 Nelson, et al, ANJR,2001

Ihn,et al,Acta Neurochirurgica, 2006

Mu,et al,Chinese Medical Journal,2008

Lee,et al, AJNR, 2011

Ko, et al, Clinical Neurology\&Neurosurgery,2015

Chalouhi,et al,AJNR,2013

Wu, et al, Journal of Turkish Neurosurgery,2014

Subgroup $C\left(I^{\wedge} 2=79.88 \%, P=0.000\right)$

Sani, et al, Neurosurgical Focus,2005

Binodi,et al, Neurosurgery,2007

Yavuz,et al,JNS,2007

De Keukeleire, et al, AJNR,2008

Peluso,et al. AJNR,2008

Huang, et al, AJNR, 2009

Gao, et al, Neurological research,2011

Maldonado, et al.AJNR,2011

Spiotta, et al,2011,Neurosurgery, 2011

Lee,et al, Journal of Koeran Neurosurgery,2012

Liu, et al,Interventional Neuroradilogy ,2012

Mangubat, et al, Neurointervention, 2012

Wakhloo, et al,AJNR, 2012

Zhao,et al,AJNR,2012

Chalouhi,et al,AJNR,2013 2

Cho,et al,AJNR, 2013

Geyik, et al,AJNR,2013

Yavuz,et al,AJNR,2013

Aguilar-Perez,et al,AJNR, 2014

Bartolini,et al,AJNR,2014

Gory, et al, Neurosurgery,2014

Jeon,et al,Acta Neuochirurgica,2014

Wu, et al, Journal of Turkish Neurosurgery,2014 2

Zhang,et al, Journal of Clinical Neuroscience ,2014

Fiorella, et al, J Neurointerv Surg,2015

Poncyljusz, et al. J Neurointerv Surg,2015

Katsaridis,et al, Am J Neuroradiol, 2006

Lee, et al, Interv Neuroradiol,2007

Kim, et al, Interv Neuroradiol,2008

Lubicz, et al, Neuroradiology,2009

Sedat, et al,Neuroradiology,2009,

Subgroup $S\left(I^{\wedge} 2=96.29 \%, P=0.000\right)$

Overall $\left(I^{\wedge} 2=95.48 \%, P=0.000\right)$
Estimate (95\% C.I.)

$0.710(0.550,0.869)$

$0.643(0.392,0.894)$

$0.750(0.560,0.940)$

$0.929(0.738,1.119)$

$0.900(0.807,0.993)$

$0.912(0.839,0.985)$

$0.969(0.883,1.054)$

$0.500(0.327,0.673)$

$0.742(0.651,0.833)$

$0.801(0.709,0.892)$

$0.900(0.714,1.086)$

$0.567(0.389,0.744)$

$0.944(0.839,1.050)$

$0.500(0.154,0.845)$

$0.571(0.312,0.831)$

$0.917(0.760,1.073)$

$0.855(0.801,0.910)$

$0.647(0.533,0.761)$

$0.632(0.415,0.848)$

$0.958(0.845,1.071)$

$0.556(0.231,0.880)$

$0.667(0.449,0.884)$

$0.650(0.565,0.735)$

$0.818(0.590,1.046)$

$0.754(0.652,0.855)$

$0.704(0.531,0.876)$

$0.983(0.971,0.995)$

$0.247(0.185,0.309)$

$0.591(0.385,0.796)$

$0.859(0.785,0.933)$

$0.600(0.471,0.729)$

$0.810(0.642,0.977)$

$0.755(0.635,0.876)$

$0.625(0.388,0.862)$

$0.750(0.590,0.910)$

$0.821(0.735,0.906)$

$0.985(0.943,1.027)$

$0.469(0.296,0.642)$

$0.740(0.642,0.838)$

$0.794(0.658,0.930)$

$0.711(0.566,0.855)$

$0.730(0.651,0.810)$

$0.745(0.680,0.810) 1612 / 2127$

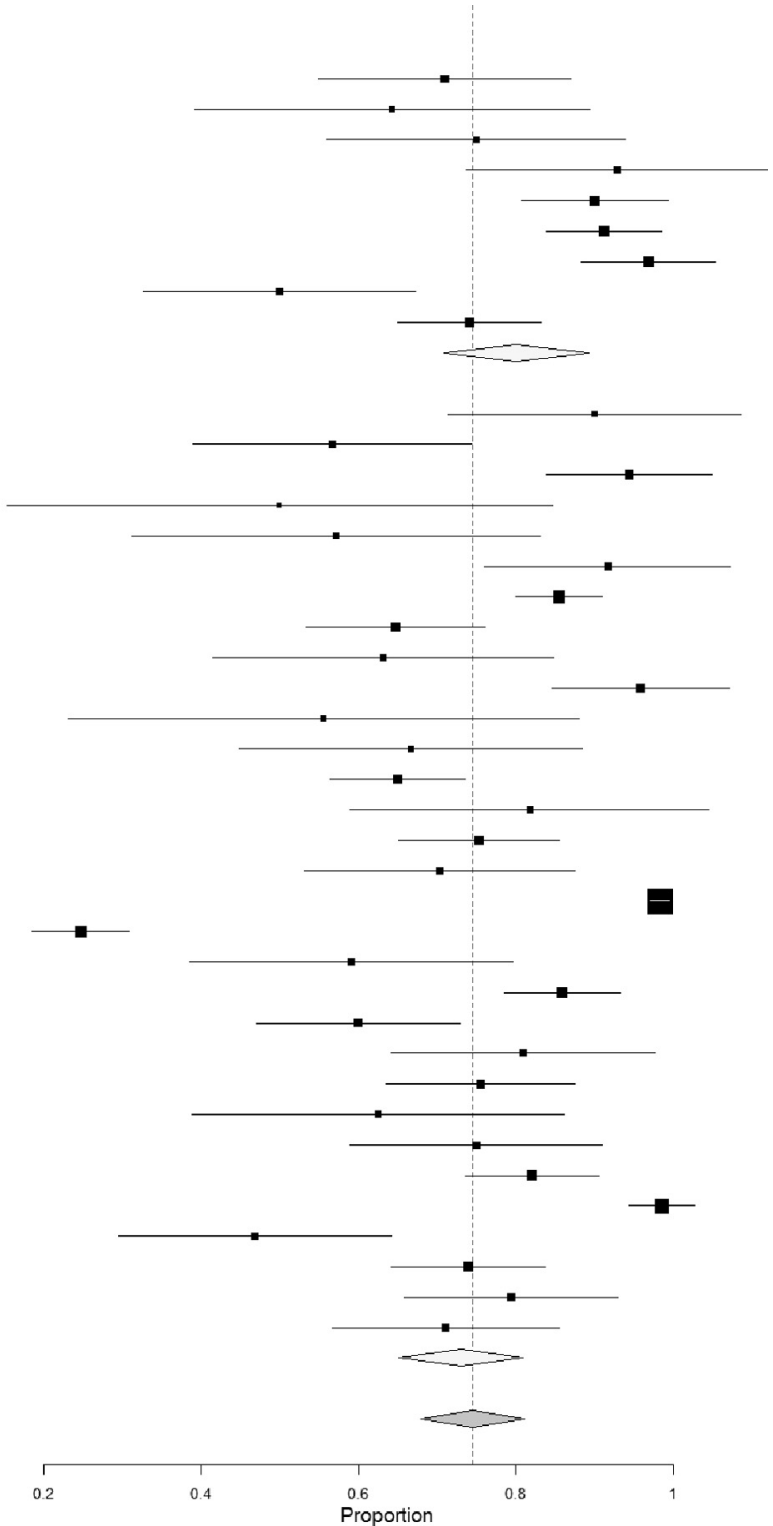

FIG 3. Forest plot for long-term complete or near-complete angiographic occlusion by treatment type.

Results of meta-analysis

\begin{tabular}{|c|c|c|c|c|c|c|c|c|}
\hline & All & $\mathrm{I}^{2}(\%)$ & $\begin{array}{l}\text { Coil Without } \\
\text { Stent-Assistance }\end{array}$ & $\mathrm{I}^{2}(\%)$ & Stent-Coil & $I^{2}(\%)$ & $P$ & $\begin{array}{l}\text { Wide-Neck } \\
\text { Bifurcation }\end{array}$ \\
\hline Initial complete or near-complete occlusion & $57.4(48.1-66.8)$ & 97 & $68.0(54.3-81.6)$ & 90 & $54.4(43.0-66.8)$ & 98 & .01 & $60.0(42.7-77.3)$ \\
\hline $\begin{array}{l}\text { Long-term complete or near-complete } \\
\text { occlusion }\end{array}$ & $74.5(68.0-81.0)$ & 95 & $80.1(70.9-89.2)$ & 80 & $73.0(65.1-81.0)$ & 96 & .38 & $71.9(52.6-91.1)$ \\
\hline Aneurysm recanalization & $9.4(7.1-11.7)$ & 67 & $10.3(4.3-16.4)$ & 59 & $9.2(6.7-11.7)$ & 69 & .17 & $9.8(7.1-12.5)$ \\
\hline Retreatment & $5.8(4.1-7.5)$ & 55 & $5.5(1.7-9.2)$ & 40 & $5.7(3.8-7.7)$ & 58 & .47 & $5.2(1.9-8.4)$ \\
\hline Long-term good neurologic outcome & $91.4(88.5-94.2)$ & 75 & $89.0(82.0-96.1)$ & 57 & $91.8(88.6-95.1)$ & 78 & .53 & $86.3(78.1-93.4)$ \\
\hline Procedure-related morbidity & $2.6(1.7-3.4)$ & 26 & $1.9(0.0-3.7)$ & 0 & $2.8(1.7-3.8)$ & 37 & .33 & $4.4(1.9-7.0)$ \\
\hline Procedure-related mortality & $1.0(0.6-1.5)$ & 0 & $1.1(0.0-2.3)$ & 0 & $1.0(0.6-1.5)$ & 0 & .92 & $0.9(0.1-1.8)$ \\
\hline
\end{tabular}

(95\% CI, 82.0\%-96.1\%), and the rate of good neurologic outcome for wide-neck bifurcation aneurysms was $86.3 \%$ (95\% CI, 78.1\%-93.4\%). These data are summarized in the Table.

\section{Heterogeneity}

Heterogeneity of treatment effect across studies was evaluated by using the $\mathrm{I}^{2}$ statistic, in which $\mathrm{I}^{2}>50 \%$ suggests substantial heterogeneity. ${ }^{10}$ There was no substantial heterogeneity for procedure-related morbidity and mortality for any of the groups. There was substantial heterogeneity for initial and long-term angiographic outcomes, long-term good neurologic outcome, and aneurysm recanalization rates for all study groups. $\mathrm{I}^{2}$ values were approximately $50 \%$ for retreatment for all groups. 


\section{DISCUSSION}

Our meta-analysis including 38 studies and over 2000 patients with wide-neck aneurysms treated with coiling and stent-assisted coiling demonstrated that though these techniques are generally safe, initial and long-term complete and near complete occlusion rates are not ideal. Overall, approximately $75 \%$ of aneurysms had complete or near-complete occlusion at last angiographic followup, and approximately $6 \%$ of aneurysms were retreated. Wideneck aneurysms located at bifurcation points such as the MCA and basilar artery had complete occlusion rates of $72 \%$ and retreatment rates of approximately 5\%. These findings are important because they suggest that the continued development of newer devices and techniques aimed at treating these complex lesions is needed to improve angiographic outcomes.

In general, treatment of wide-neck and wide-neck bifurcation aneurysms by using endovascular techniques is challenging. Embolization of these aneurysms without the use of adjunctive devices is difficult because of instability of the coil mass leading to the risk of coil protrusion into the parent artery. The risk of coil protrusion often makes attenuated packing of the aneurysm difficult or impossible to achieve, which can lead to lower rates of complete occlusion. ${ }^{11}$ Neurovascular stents act as a scaffold to prevent coil protrusion into the parent artery. Over the past 2 decades, a number of improvements to flexibility and delivery have been made to neurovascular stents, and as a result, these devices are increasingly used in the treatment of complex intracranial aneurysms. ${ }^{11,12}$ A recently published systematic review of stent-assisted coiling of wide-neck aneurysms including 702 aneurysms treated through 2011 demonstrated initial and longterm complete occlusion rates of $46 \%$ and $72 \%$, respectively, and recanalization rates of $13 \% .{ }^{11}$ However, improvements in the design of neurovascular stents and the advent of newer neurovascular stents will likely result in improvements in angiographic outcomes for stent-assisted coiling of wide-neck aneurysms. In fact, a recently published multicenter registry on the use of the LVIS stent (MicroVention, Tustin, California) in treating wide-neck aneurysms found complete and near-complete occlusion rates of $82 \%$ and $6 \%$, respectively. ${ }^{13}$

Flow diverters such as the Pipeline Embolization Device (Covidien, Irvine, California) and Silk Device (Balt Extrusion, Montmorency, France) are increasingly being used in the treatment of complex, wide-neck intracranial aneurysms, particularly aneurysms of the ICA. In the Pipeline for Uncoilable or Failed Aneurysms clinical trial including over 100 patients with large and giant wide-neck ICA aneurysms, the rate of complete angiographic occlusion at 12 months was $87 \%$, with only $5.5 \%$ of patients having residual aneurysm. ${ }^{14}$ There was even improvement in angiographic results with time; more than $95 \%$ of patients had complete angiographic occlusion at 5 years. ${ }^{15}$ However, it is important to note that flow-diverter treatment of bifurcation aneurysms can be challenging and is associated with higher morbidity rates and lower occlusion rates that those reported for aneurysms of the ICA. In a study of 14 patients with MCA bifurcation aneurysms treated with flow diverters, Caroff et al ${ }^{16}$ found complete occlusion rates of $62 \%$ and procedure-related morbidity rates of over 20\%. Gawlitza et $\mathrm{al}^{17}$ found occlusion rates of just 33\% after treatment of
MCA and anterior communicating artery aneurysms with flow-diverter stents. The challenging factors for treating bifurcation aneurysms with flow diverters include the need to cover branch vessels and perforators with the flow-diverter stent and technical challenges with device delivery.

Over the past several years, intrasaccular flow diverters such as the Woven EndoBridge system have emerged as effective techniques for the treatment of wide-neck bifurcation aneurysms. These devices function by disrupting intra-aneurysmal flow and creating intra-aneurysmal thrombosis. ${ }^{18}$ The devices are designed to essentially plug the neck of the aneurysm sac and prevent inward blood flow. One advantage of the Woven EndoBridge device is the lack of a need for dual antiplatelet therapy, which is especially important in the setting of treating ruptured aneurysms. The Woven EndoBridge has been the subject of numerous clinical studies designed to investigate the efficacy of treating intracranial, wide-neck bifurcation aneurysms. Thus far, early small studies suggest that the Woven EndoBridge device is associated with higher angiographic occlusion rates than stent-assisted coiling in the treatment of wide-neck bifurcation aneurysms with similar low rates of procedure-related morbidity and mortality. In a study of 52 patients with 55 aneurysms, Behme et $\mathrm{al}^{19}$ found favorable angiographic outcomes in $75 \%$ of cases, with all patients experiencing good neurologic outcomes on long-term follow-up. In a multicenter study of 45 patients with 45 aneurysms, Lubicz et $\mathrm{al}^{20}$ found complete or near complete occlusion in $90 \%$ of cases, with good long-term neurologic outcome rates of $93 \%$. The WEB Clinical Assessment of IntraSaccular Aneurysm Therapy (WEBCAST) study, which examined outcomes for treatment of wide-neck bifurcation aneurysms in 51 patients, found complete and nearcomplete occlusion rates of $85 \%$ and procedure-related morbidity and mortality rates of $2 \%$ and $0 \%$, respectively. ${ }^{21}$

\section{Limitations}

Although data in this meta-analysis were derived from a strictly defined patient population with at least 6 months of follow-up, our study has limitations. Almost all studies were retrospective case series; thus, our study undoubtedly suffers from selection bias. In our assessment of study risk of bias, most of the studies had a medium to high risk of bias. $\mathrm{I}^{2}$ values were above $50 \%$ for most outcomes, indicating substantial heterogeneity. In addition, most studies did not have neurologic outcomes assessed by an independent physician, and these assessments were not blinded to the aneurysm treatment used. Publication bias is also possible because centers with better outcomes may have been more prone to report their results. We did not have access to individual patient data and, consequently, could not investigate the effect of important factors (including age, aneurysm size and location, medical comorbidities, etc) on angiographic and clinical outcomes. We were unable to stratify outcomes by aneurysm rupture status; however, most aneurysms included in this study were unruptured. Overall, the quality of evidence (confidence in estimates) is low because of imprecision, heterogeneity, and methodologic limitations of the included studies. ${ }^{22,23}$ Nevertheless, this systematic review and meta-analysis provides useful data to share with families when discussing the possible outcomes of stent-assisted coiling of wide-neck and wide-neck bifurcation aneurysms. In 
addition, this study could serve as a benchmark for which to compare results of newer stents, flow diverters, and intrasaccular flow diverters.

\section{CONCLUSIONS}

Our study of angiographic and clinical outcomes for patients with wide-neck aneurysms demonstrates that endovascular coiling, with or without stent-assisted coiling, is generally safe, with low rates of perioperative morbidity and mortality. Initial and longterm angiographic outcomes were satisfactory, but not ideal, and lower than those reported for treatment of similar aneurysms with newer technologies such as intraluminal and intrasaccular flow diverters. Future comparative clinical trials could be considered to identify the best treatments for wide-neck and wide-neck bifurcation aneurysms.

Disclosures: Giuseppe Lanzino-UNRELATED: Consultancy: Covidien/Medtronic.* David F. Kallmes—UNRELATED: Board Membership: GE Healthcare,* Comments: Cost effectiveness board; Consultancy: Medtronic, ${ }^{*}$ Comments: Planning and implementing clinical trials; Grants/Grants Pending: MicroVention,* Medtronic, ${ }^{*}$ Codman, ${ }^{*}$ Surmodics, ${ }^{*}$ Sequent, ${ }^{*}$ NeuroSigma, ${ }^{*}$ Comments: Preclinical research and clinical trials. ${ }^{\star}$ Money paid to the institution.

\section{REFERENCES}

1. Moret J, Cognard C, Weill A, et al. The "remodelling technique" in the treatment of wide neck intracranial aneurysms: angiographic results and clinical follow-up in 56 cases. Interv Neuroradiol 1997;3: 21-35 Medline

2. Nakahara T, Hidaka T, Kutsuna M, et al. Intraaneurysmal embolization for wide-necked aneurysms: remodeling technique, combined neck-clipping and coiling therapy, scaffolding technique. Interv Neuroradiol 2000;6(suppl 1):95-101 Medline

3. Biondi A, Janardhan V, Katz JM, et al. Neuroform stent-assisted coil embolization of wide-neck intracranial aneurysms: strategies in stent deployment and midterm follow-up. Neurosurgery 2007;61: 460-68; discussion 468-69 CrossRef Medline

4. Mu SQ, Yang XJ, Li YX, et al. Endovascular treatment of widenecked intracranial aneurysms using of "remodeling technique" with the HyperForm balloon. Chin Med J (Engl) 2008;121:725-29 Medline

5. Lee JY, Seo JH, Cho YD, et al. Endovascular treatment of wide-neck intracranial aneurysms using a microcatheter protective technique: results and outcomes in 75 aneurysms. AJNR Am J Neuroradiol 2011; 32:917-22 CrossRef Medline

6. Bartolini B, Blanc R, Pistocchi S, et al. "Y" and " $\mathrm{X}$ " stent-assisted coiling of complex and wide-neck intracranial bifurcation aneurysms. AJNR Am J Neuroradiol 2014;35:2153-58 CrossRef Medline

7. Zhang JZ, Yang PF, Huang QH, et al. Stent-assisted coiling strategies for the treatment of wide-necked basilar artery bifurcation aneurysms. J Clin Neurosci 2014;21:962-67 CrossRef Medline

8. Ko JK, Han IH, Cho WH, et al. Crossing Y-stent technique with dual open-cell stents for coiling of wide-necked bifurcation aneurysms. Clin Neurol Neurosurg 2015;132:54-60 CrossRef Medline

9. DerSimonian R, Laird N. Meta-analysis in clinical trials. Control Clin Trials 1986;7:177-88 CrossRef Medline

10. Higgins JP, Thompson SG, Deeks JJ, et al. Measuring inconsistency in meta-analyses. BMJ 2003;327:557-60 CrossRef Medline

11. McLaughlin N, McArthur DL, Martin NA. Use of stent-assisted coil embolization for the treatment of wide-necked aneurysms: a systematic review. Surg Neurol Int 2013;4:43 CrossRef Medline

12. McDonald JS, Norgan AP, McDonald RJ, et al. In-hospital outcomes associated with stent-assisted endovascular treatment of unruptured cerebral aneurysms in the USA. J Neurointerv Surg 2013;5: 317-20 CrossRef Medline

13. Poncyljusz W, Biliński P, Safranow K, et al. The LVIS/LVIS Jr. stents in the treatment of wide-neck intracranial aneurysms: multicentre registry. J Neurointerv Surg 2015;7:524-29 CrossRef Medline

14. Becske T, Kallmes DF, Saatci I, et al. Pipeline for uncoilable or failed aneurysms: results from a multicenter clinical trial. Radiology 2013; 267:858-68 CrossRef Medline

15. Brinjikji W, Kallmes DF, Becske T. 5 year follow up results from the Pipeline for Uncoilable or Failed Aneurysms trial. Stroke 2015:LB P1

16. Caroff J, Neki H, Mihalea C, et al. Flow-diverter stents for the treatment of saccular middle cerebral artery bifurcation aneurysms. AJNR Am J Neuroradiol 2016;37:279-84 CrossRef Medline

17. Gawlitza M, Januel AC, Tall P, et al. Flow diversion treatment of complex bifurcation aneurysms beyond the circle of Willis: a single-center series with special emphasis on covered cortical branches and perforating arteries. J Neurointerv Surg 2016;8:481-87 CrossRef Medline

18. Pierot L, Liebig T, Sychra V, et al. Intrasaccular flow-disruption treatment of intracranial aneurysms: preliminary results of a multicenter clinical study. AJNR Am J Neuroradiol 2012;33:1232-38 CrossRef Medline

19. Behme D, Berlis A, Weber W. Woven EndoBridge intrasaccular flow disrupter for the treatment of ruptured and unruptured wide-neck cerebral aneurysms: report of 55 cases. AJNR Am J Neuroradiol 2015; 36:1501-06 CrossRef Medline

20. Lubicz B, Klisch J, Gauvrit JY, et al. WEB-DL endovascular treatment of wide-neck bifurcation aneurysms: short- and midterm results in a European study. AJNR Am J Neuroradiol 2014;35:432-38 CrossRef Medline

21. Pierot L, Costalat V, Moret J, et al. Safety and efficacy of aneurysm treatment with WEB: results of the WEBCAST study. J Neurosurg 2016;124:1250-56 CrossRef Medline

22. Balshem H, Helfand $M$, Schünemann HJ, et al. GRADE guidelines: 3 . Rating the quality of evidence. J Clin Epidemiol 2011;64:401-06 CrossRef Medline

23. Guyatt GH, Oxman AD, Kunz R, et al. GRADE guidelines 6. Rating the quality of evidence-imprecision. J Clin Epidemiol 2011;64: 1283-93 CrossRef Medline 